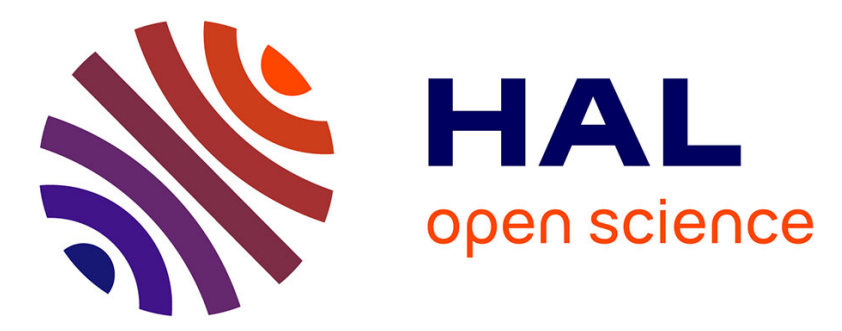

\title{
Temperature-based energy solver coupled with tabulated thermodynamic properties - Application to the prediction of macrosegregation in multicomponent alloys
} Ali Saad, Charles-André Gandin, Michel Bellet

\section{- To cite this version:}

Ali Saad, Charles-André Gandin, Michel Bellet. Temperature-based energy solver coupled with tabulated thermodynamic properties - Application to the prediction of macrosegregation in multicomponent alloys. Computational Materials Science, 2015, 99, pp.221-231. 10.1016/j.commatsci.2014.12.009 . hal-01111022

HAL Id: hal-01111022

https://hal-mines-paristech.archives-ouvertes.fr/hal-01111022

Submitted on 9 Jan 2017

HAL is a multi-disciplinary open access archive for the deposit and dissemination of scientific research documents, whether they are published or not. The documents may come from teaching and research institutions in France or abroad, or from public or private research centers.
L'archive ouverte pluridisciplinaire HAL, est destinée au dépôt et à la diffusion de documents scientifiques de niveau recherche, publiés ou non, émanant des établissements d'enseignement et de recherche français ou étrangers, des laboratoires publics ou privés. 


\title{
Temperature-based energy solver coupled with tabulated thermodynamic properties - Application to the prediction of macrosegregation in multicomponent alloys
}

\author{
Ali SAAD, Charles-André GANDIN and Michel BELLET \\ MINES ParisTech, Centre de Mise en Forme des Matériaux \\ UMR CNRS 7635, CS10207, 06904 Sophia Antipolis, France \\ charles-andre.gandin@mines-paristech.fr
}

\section{Keywords}

Finite element method, energy conservation, thermodynamics, solidification, macrosegregation

\begin{abstract}
We present a new algorithm for solving energy balance in phase change problems, particularly in solidification with macrosegregation. The algorithm is based on a nonlinear temperature evaluation using the average enthalpy which is provided by i) tabulated phase transformation paths and ii) tabulated phase properties. The compatibility of this method with tabulations using a thermodynamic database, allows simulating solidification at equilibrium with multiple phase transformations for binary and multicomponent alloys. The method has been validated and applied to three-dimensional cases with macrosegregation: a binary $\mathrm{Sn}-3 \mathrm{wt} . \% \mathrm{~Pb}$ alloy and a ternary $\mathrm{Fe}-2 \mathrm{wt} . \% \mathrm{C}-30 \mathrm{wt} . \% \mathrm{Cr}$ alloy. For the latter case, predictions include composition maps for $\mathrm{C}$ and $\mathrm{Cr}$ due to thermosolutal instability leading to freckle formation and the subsequent distributions of liquid, $\mathrm{BCC}, \mathrm{FCC}, \mathrm{M}_{7} \mathrm{C}_{3}$ and Cementite phases. Compared with a previously published enthalpy method, the temperature-based energy solver shows similar accuracy and faster computational time.
\end{abstract}




\section{Introduction}

Macrosegregation, a well distinguished defect in alloy solidification, has been a main research topic in the metallurgy community for the last few decades [1]. It develops within several physical scales: at a microscopic scale, solute partitioning between the liquid and solid phases creates composition gradients at the interface between the phases, known as microsegregation [2]. Macroscopically, fluid flow in the liquid phase as well as other mechanical factors, such as deformation of the mush [3], [4], solidification shrinkage [5] and transport of grains [6], [7] may redistribute unevenly the rejected chemical species. These transport phenomena gradually enrich or deplete the melt located outside an established mushy zone, leading to regions with significant composition differences, hence altering the properties in the finished product. To model macrosegregation, a minimum of four conservation principles are used: conservation of mass, momentum, chemical species and energy. The phase change literature contains a wealth of numerical methods to solve energy conservation in solidifying alloys. A comprehensive overview of these methods is given by Swaminathan and Voller [8]. The corresponding equation associates the total average enthalpy to the temperature via intrinsic alloy properties, such as the heat capacity of the phases and the latent heat associated with the phase transformations. However, in the course of solidification with macrosegregation, these properties may change because the average composition may vary significantly: the transformation paths are then modified, as well as the phases' composition and heat capacity. Similarly, the latent heat of phase transformations is not a constant that could be distributed as a function of the phase fractions assuming only temperature-dependent phases' properties, as often found in the literature [9]. It is thus impossible to establish a priori the dependence of the enthalpy with respect to temperature when macrosegregation takes place, even in the case of full thermodynamic equilibrium between phases.

The current work discusses a suitable numerical scheme based on an enthalpy method, already used in the literature to alleviate this macrosegregation-related problem [8], [10]. Secondly, we introduce a modified formulation, using the effective heat capacity method that increases the original scheme's efficiency. The current method is thus an enthalpy method that makes use of a temperature-based solver. Moreover, it uses tabulated thermodynamic quantities (solidification paths, phases' enthalpy and composition) in a range of average compositions and temperatures as found in the literature [11]-[13], with the aim of evaluating the total average enthalpy as well as the effective heat capacity. The novelty of the modified method resides in the use of thermodynamic tabulations without losing the advantages of the previous method, thus yielding faster computation times while maintaining a good accuracy. Finally, test cases are presented.

\section{Thermodynamic Considerations}

\subsection{Volume averaging}

A volume averaging technique was suggested to deal with the presence of multiple phases [14]. It locally considers a Representative Volume Element (RVE) that contains several phases at a mesoscopic scale. We represent, for each unknown $\psi$, an intrinsic volume average, (also denoted in the literature), corresponding to a phase $\phi$. The volume average for this unknown in the RVE, hence averaged over all the present phases writes: 
where denotes the volume fraction of phase $\phi$ in the RVE. It should be emphasized that the averaging technique applies to virtually all thermodynamic variables (enthalpy, density ...). Among these variables, the temperature is considered to be uniform in the RVE. Applying the volume averaging technique to the energy conservation principle along with interfacial balances between the phases, results in the following averaged equation [15]:

Eq. 2

where $\rho$ stands for the density, $h$ the mass enthalpy, $v$ the velocity field, $\kappa$ the thermal conductivity, $T$ the temperature and a possible volume heat source. While the latter source is zero in the rest of this contribution, we keep it to maintain a general formulation of the energy conservation. Eq. 2 is the standard averaged form of the energy conservation equation used in non-stationary phase change problems. Once the variational form has been discretized in space and time, two possible resolution schemes emerge: the first is an explicit forward Euler scheme which gives rise to a linear equation where the temperature denoted by is known at time t. This requires very small time steps in the current context, which limits the solver's usability at the scale of industrial applications. The second scheme is the backward Euler or full implicit discretization where terms are function of ${ }^{t}$. It leads to a nonlinear equation with 2 interdependent

unknowns, and $t$. It is clear that the nature of the temperature-enthalpy relationship plays a central role when formulating the resolution strategy of this nonlinear equation. Generally, it is admitted that, depending on the resolution strategy, it is necessary to express enthalpy as a function of temperature or vice-versa, together with associated partial derivatives, or $\quad$.

\subsection{The temperature-enthalpy relationship}

In solidification problems, additional variables are involved in Eq. 1 and Eq. 2, like the transformation path that defines the history of the phase fractions, as well as the average chemical composition $\quad\rangle, i$ being the index of the chemical species (only the solutes are considered). The temperature-enthalpy relation averaged over the phases in a given RVE writes:

Eq. 3

Note that the volume average enthalpy is approximated by the product

in the current work. As stated in the introduction, it becomes clear from Eq. 3 that phase properties, i.e. average phase density, , and enthalpy, are temperature and composition dependent. This equation is the key to convert the average volume enthalpy to temperature (through a procedure named $\mathrm{H} 2 \mathrm{~T})$ or vice-versa $(\mathrm{T} 2 \mathrm{H})$. The values of the different phase fractions (solidification path) and phase enthalpies are thus needed to close the relation.

\subsection{Tabulation of properties}

The complexity of performing a thermodynamic conversion is directly linked to the simplicity of 
determining the alloy properties, namely the phase fractions and phase enthalpies. In the case of binary alloys and with several assumptions with respect to the system (e.g., linear monovariant temperature-composition relationships, constant heat capacity of phases and constant latent heat of transformations, equilibrium approximations between phases) analytical calculations are often used to determine the properties. Nevertheless, analytical relations are more complex or even impossible to derive in the case of multicomponent alloys ( $i \quad 1)$. To overcome this problem, one can resort to thermodynamic databases and phase equilibrium calculations to tabulate the transformation paths and the phase enthalpies for a given range of temperatures and average compositions. It is a handy solution for two main reasons: first, the conversion is merely a binary search in a table; secondly, it is a simple solution for coupling with macrosegregation. In this way, phase fractions are tabulated as functions of temperature and average composition, while for each phase the mass enthalpy, $\phi$, and the density, $\phi$, are tabulated as functions of temperature and phase intrinsic average compositions $\phi$, as well as other possible parameters. Figure 1 summarizes the steps in order to perform a temperature-to-enthalpy (T2H) conversion using the predefined tabulation approach. In step 1, the transformation path is acquired for each average composition and temperature to determine the list of phases, their volume fractions and their intrinsic compositions $\phi$. In step 2, the phase enthalpy and density are determined by searching for the temperature and the already known phase composition $\quad \phi$. In step 3, the average volume enthalpy is computed from the volume fraction, density and mass enthalpy of phases using Eq. 3.

\begin{tabular}{|c|c|c|c|}
\hline Step \# & $\mathbf{1}$ & $\mathbf{2}$ & $\mathbf{3}$ \\
\hline Inputs & $\{\mathrm{T}\rangle\}$, & $\{\mathrm{T}, \quad\}$ & $\left\{g^{\phi}, \quad\right\}$ \\
\hline Outputs & $\{, \quad\}$ & $\{<, \quad\}$ & $\{\langle\rangle\}$ (Eq. 3) \\
\hline
\end{tabular}

Figure 1: Tabulation processing for a $\mathrm{T} 2 \mathrm{H}$ procedure

The methodology to build the tabulations is straightforward. It is based on two main scans. On the one hand, intervals for the variation of the average composition are chosen from the known alloy composition. These variations have to cover the extreme values adopted during the simulation, which are not known a priori. An interval is also selected for the variation of temperature. The latter is easier to determine as it usually starts from the initial melt temperature and goes down to the room temperature in a standard casting simulation. For these intervals, a systematic scan is made with chosen steps in each composition and T, during which a thermodynamic equilibrium is computed. The outputs are the number of phases encountered, together with their fraction and intrinsic composition. The minimum and maximum intrinsic composition for each phase could then be determined. On the other hand, for each phase, a scan of the intrinsic composition and temperature is made to compute the intrinsic properties. The same temperature interval and step as defined earlier are used. This strategy based on full thermodynamic equilibrium means that it is limited to the so-called lever rule approximation.

Regarding the enthalpy-to-temperature conversion (H2T), a backward iterative $\mathrm{T} 2 \mathrm{H}$ search is performed. For a known composition $\quad\rangle$, denoting $k$ the iteration index to convert the enthalpy , we start with an initial guess for temperature then convert it to an enthalpy with the T2H conversion. 
Using an appropriate nonlinear algorithm (Brent is the most versatile in our case), we aim at minimizing the following residual:

|. Once the algorithm has converged, the temperature is the result of the H2T conversion. It is inferred that the first conversion (T2H) is a direct one whereas the latter $(\mathrm{H} 2 \mathrm{~T})$ is indirect and requires a series of iterative steps; each step being a single T2H resolution. In other words, a H2T conversion is a backward search for a temperature, hence it's slower. This conversion's speed lag is aggravated when tabulations increase in size (e.g. large number of temperature and composition steps) and complexity (e.g., multicomponent industrial alloys used in casting), since the search gets more complicated with the increasing number of input columns (one column for each alloying element).

\section{Numerical method}

The finite element method is used to solve the energy conservation as expressed by Eq. 2. A test function belonging to the Hilbertian Sobolev space of continuous integrable test functions is used to formulate the integral variational form of Eq. 2 [16]. A Fourier boundary condition is considered on the domain boundary $\Omega$. The domain is discretized using first-order linear simplexes defined by their number of local nodes (denoted " $N$ Loc"): triangles in 2D with and tetrahedra in 3D with 4 . The outcome is a residual that we aim to minimize so that the conservation principle is satisfied. Assuming a static solid phase and an incompressible liquid phase, it can be shown that the second term of Eq. 2 can be cast into the expression ). Therefore, its weak (variational) form is defined as follows:

Eq. 4

The steps for discretizing in time and space the previous equation are detailed in the literature [2], [15]. As for enthalpy and temperature, they are spatially discretized in each finite element using interpolations functions $N_{j}$, thus defining the nodal values and $T_{j}$, respectively:

Eq. 5

Eq. 6

Note that is a volumetric enthalpy. The Galerkin formulation gives the following expression for the residual contribution at a mesh node $i$ for time step $t$ in a local element ${ }_{E}$ :

Eq. 7

where 
transient term

contribution

advection

contribution

conductivity

contribution boundary

condition

contribution

The surface integrals $K 2_{i j}^{E}$ and $F_{i}^{E}$ are related to a Fourier-type boundary condition, with $h_{\text {ext }}$ as a coefficient of heat exchange and $T_{\text {ext }}$ as the external temperature far from the boundary. The energy conservation principle is satisfied when the sum of the residual contributions coming from all the mesh elements is zero. In other words, the following global residual defined by the assembly of these contributions, should be minimized:

Eq. 8

where the global matrices $M_{i j}, A_{i j}, K 1_{i j}, K 2_{i j}, F_{i}$ and $S_{i}$ contain respectively, after an assembly step, the contributions of the local matrices $M_{i j}^{E}, A_{i j}^{E}, K 1_{i j}^{E}, K 2_{i j}^{E}, F_{i}^{E}$ and $S_{i}^{E}$ from each discretized element in the domain $\Omega$. Accordingly, the indices $i$ and $j$ refer to global node numbers, where the total number of nodes denoted by NbGlob. It is clear that the global residual, inherits the dependence between enthalpy and temperature. This is shown in Eq. 8 where the average volume enthalpy is a function of the temperature. It infers that this residual is a non-linear function; therefore minimizing it requires an iterative non-linear algorithm. Our choice settles on the Newton-Raphson method, known for its quadratic convergence speed. A solidification problem can induce severe non-linearities from the release of the latent heat (which itself is temperature-composition dependent) and the variations of the thermophysical properties of the alloy with respect to temperature and average composition. This algorithm could thus treat such variations. Considering the link between enthalpy and temperature, Eq. 8 may be solved either for enthalpy or for temperature as a nodal unknown; hence both formulations are presented hereafter.

\subsection{Enthalpy-based approach (Hsolver)}

The residual is re-written using a Taylor series expansion to the first order for a nonlinear iteration :

Eq. 9

Neglecting the second order terms, the suggested correction at each iteration in view of cancelling the residual and giving the new value $H_{j}{ }^{\nu}$, is given by the linear system:

Eq. 10

where is a global tangent matrix yielding the variations of the residual with respect to the enthalpy in 
the last iteration, $\quad$. If Eq. 7 is considered, then the contribution of an element writes:

Eq. 11

Eq.11 is the core of the enthalpy-based solver. The resolution of Eq.10 then yields a new estimate of the vector of nodal enthalpies ), which are the only unknowns to be solved for. Once determined at iteration $v$, convergence tests are performed as explained in section 3.3.

\subsection{Temperature-based approach (Tsolver)}

Similarly to the Hsolver, the local residual is recast for a nonlinear iteration $v$, leading this time to an iterative temperature correction:

Eq. 12

where is a global tangent matrix yielding the variations of the residual with respect to temperature at the previous iteration. The contribution of an element to this tangent matrix is evaluated as:

Eq. 13

In contrast to the previous solver, Eq. 13 is the core of the temperature-based solver. The resolution of Eq.12 yields a new estimate of the vector of nodal temperatures ), which are the only unknowns to be solved for. Once updated for iteration $v$, convergence tests are performed (see next section).

\subsection{Convergence}

The previous two sections described the iterative resolution of the same discretized energy conservation (Eq.4) by Tsolver and Hsolver. However, in both equations 11 and 13, an important term emerges from the tangent matrix evaluation describing the variations between temperature and enthalpy: (or its inverse). This term invokes the previously mentioned temperature-enthalpy tabulations which depend on the alloy composition. Consequently, (respectively its inverse) has a great influence on the convergence of the Tsolver (respectively the Hsolver). At a nonlinear iteration ), this term is written using a finite difference:

Tsolver

Eq. 14

Hsolver

Eq. 15

For the Tsolver, the enthalpy is needed to evaluate Eq. 14. In contrast, the Hsolver requires the value of to evaluate the corresponding Eq. 15. In both cases, the unknown is determined by the temperatureenthalpy relation. The indices next to the mentioned unknowns indicate that this relation is used for each 
iteration $(v)$ at each mesh node $j$, hence affecting the global resolution time between the two solvers. The Hsolver needs a $\mathrm{H} 2 \mathrm{~T}$ to evaluate $d T / d H$, whereas the Tsolver needs a $\mathrm{T} 2 \mathrm{H}$ to evaluate $d H / d T$. The flowchart in Figure 2 demonstrates the process.

It can be seen that Tsolver uses solely $\mathrm{T} 2 \mathrm{H}$ procedure and the thermodynamic tabulations to determine the enthalpy, hence the term $d H / d T$. On the other hand, Hsolver repeats the same procedure a finite number of times in order to determine a temperature output through $\mathrm{H} 2 \mathrm{~T}$ and use it to compute $d T / d H$. This algorithmic difference leverages the Tsolver in terms of computation time providing the same numerical accuracy while conserving the total system energy.

(a)

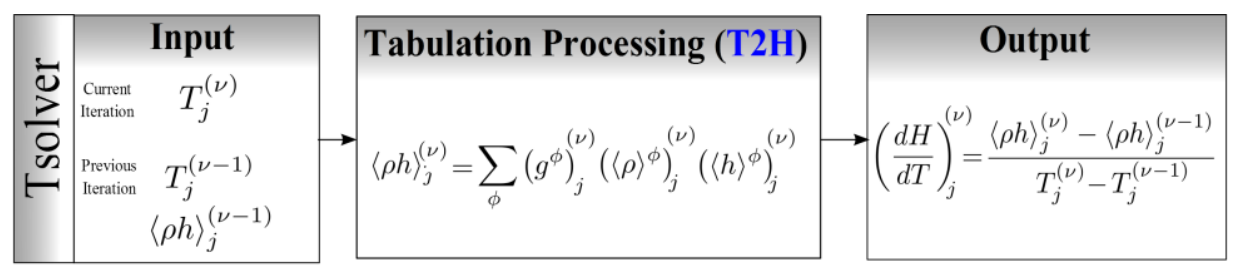

(b)
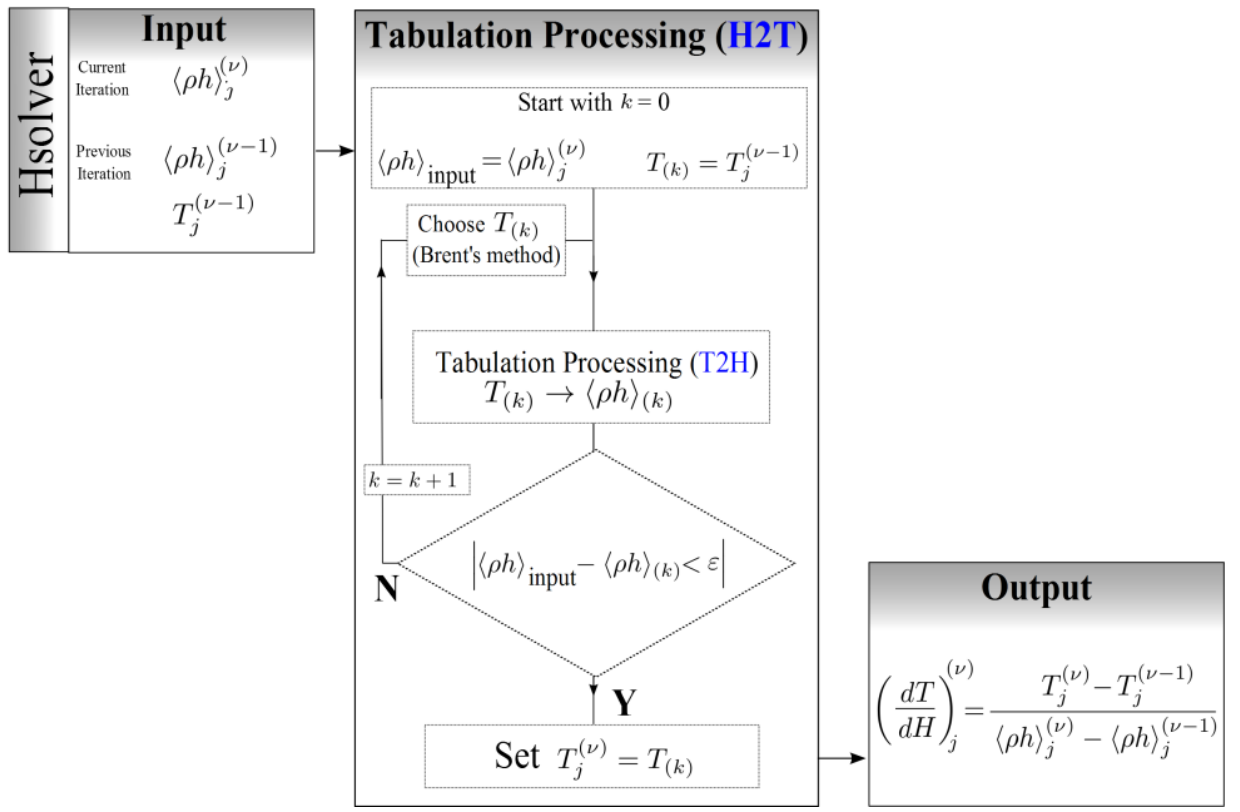

Figure 2: Flowcharts showing the steps to compute the nonlinear terms using tabulations

Convergence tests are necessary at the end of each iteration of the energy solver to determine the convergence status of the algorithm. In the context of the Tsolver for instance, the residual is re-evaluated with the newly determined temperature $T_{j}$ and enthalpy $H_{j} \quad$ so Eq. 8 rewrites:

Eq. 16

The norm of the current residual, $\|$, is compared to a fixed small value The resulting temperature variation, $\mid$, has also to verify a similar condition between two consecutive iterations. For that purpose, we compare it to another fixed value ]. 
Convergence is ultimately achieved when the following criteria are simultaneously met:

Eq. 17

A comparison of both solver formulations is done in the hereafter test cases section.

\section{Test cases for binary alloys}

\subsection{Pure diffusion}

The two solvers are first tested in a purely diffusive case for a one-dimensional solidification configuration. Predictions with a 1D front tracking model [17] is used as a benchmark. It provides solutions for the temperature and solid fraction during directional solidification of a $10 \mathrm{~cm}$ long $\mathrm{Al}-7 \mathrm{wt} . \% \mathrm{Si}$ ingot. The melt, with initial uniform temperature, is cooled with a heat exchange coefficient (assuming a Fourier boundary condition) from one side, the other side being adiabatic. All values for alloy properties, initial and boundary conditions and numerical parameters are listed in Table 1. For this simple test case, we use linear temperature dependence of the intrinsic phase enthalpies, that is and $\rho L$, where is the heat capacity per unit volume and is the latent heat per unit volume. Values for and $\rho L$, as well as for the thermal conductivities, $\quad s^{s}=\langle\quad l$, are taken constant. Moreover, a Gulliver-Scheil approximation is used to compute a single temperature - fraction of solid relationship in the absence of macrosegregation. This is done assuming a linear binary phase diagram and thus requires using the properties listed in Table 1, i.e. the segregation coefficient, $\mathrm{k}$, the liquidus slope, $\mathrm{m}_{\mathrm{L}}$, the liquidus temperature, $\mathrm{T}_{\mathrm{L}}$, and the eutectic temperature, $\mathrm{T}_{\mathrm{E}}$. Figure 3 shows the comparison with the Hsolver and Tsolver. The results are found superimposed to the front tacking solution, thus giving validation of the implementation as well as the iterative schemes presented above to solve the energy conservation.

\begin{tabular}{llll}
\hline Parameter & Symbol & Value & Unit \\
\hline Nominal composition & & 7 & $\mathrm{wt} \%$ \\
Liquidus temperature & $\mathrm{T}_{\mathrm{L}}$ & 618 & ${ }^{\circ} \mathrm{C}$ \\
Eutectic temperature & $\mathrm{T}_{\mathrm{E}}$ & 577 & ${ }^{\circ} \mathrm{C}$ \\
Segregation coefficient & $\mathrm{k}$ & 0.13 & $\mathrm{wt} \% / \mathrm{wt} . \%$ \\
Liquidus slope & $\mathrm{m}_{\mathrm{L}}$ & -6.5 & $\mathrm{wt} \%{ }^{\circ} \mathrm{C}^{-1}$ \\
Heat capacity (liquid and solid) & & $2.6 \cdot 10^{6}$ & $\mathrm{~J} \mathrm{~m}{ }^{-3} \mathrm{C}^{-1}$ \\
Enthalpy of fusion & $\rho L$ & $9.5 \cdot 10^{8}$ & $\mathrm{~J} \mathrm{~m}^{-3}$ \\
Thermal conductivity (liquid and solid) & $\kappa$ & 70 & $\mathrm{~W} \mathrm{~m}^{-1}{ }^{\circ} \mathrm{C}^{-1}$ \\
\hline Heat transfer coefficient & & 500 & $\mathrm{~W} \mathrm{~m} \mathrm{~m}^{-2} \mathrm{C}^{-1}$ \\
External temperature & $\mathrm{T}_{0}$ & 100 & ${ }^{\circ} \mathrm{C}$ \\
Initial temperature & & 800 & ${ }^{\circ} \mathrm{C}$ \\
Ingot length & & 0.1 & $\mathrm{~m}$ \\
\hline FE mesh size & & $10^{-3}$ & $\mathrm{~m}$ \\
Time step & $\varepsilon_{\mathrm{R}}$ & 0.1 & $\mathrm{~s}$ \\
Convergence criterion (residual) & $\varepsilon_{\mathrm{T}}$ & $10^{-6}$ & - \\
Convergence criterion (temperature) & $10^{-2}$ & $\mathrm{~K}$ \\
\hline
\end{tabular}

Table 1: Parameters for the pure diffusion test case with alloy $\mathrm{Al}-7$ wt. \% Si presented in Figure 3 

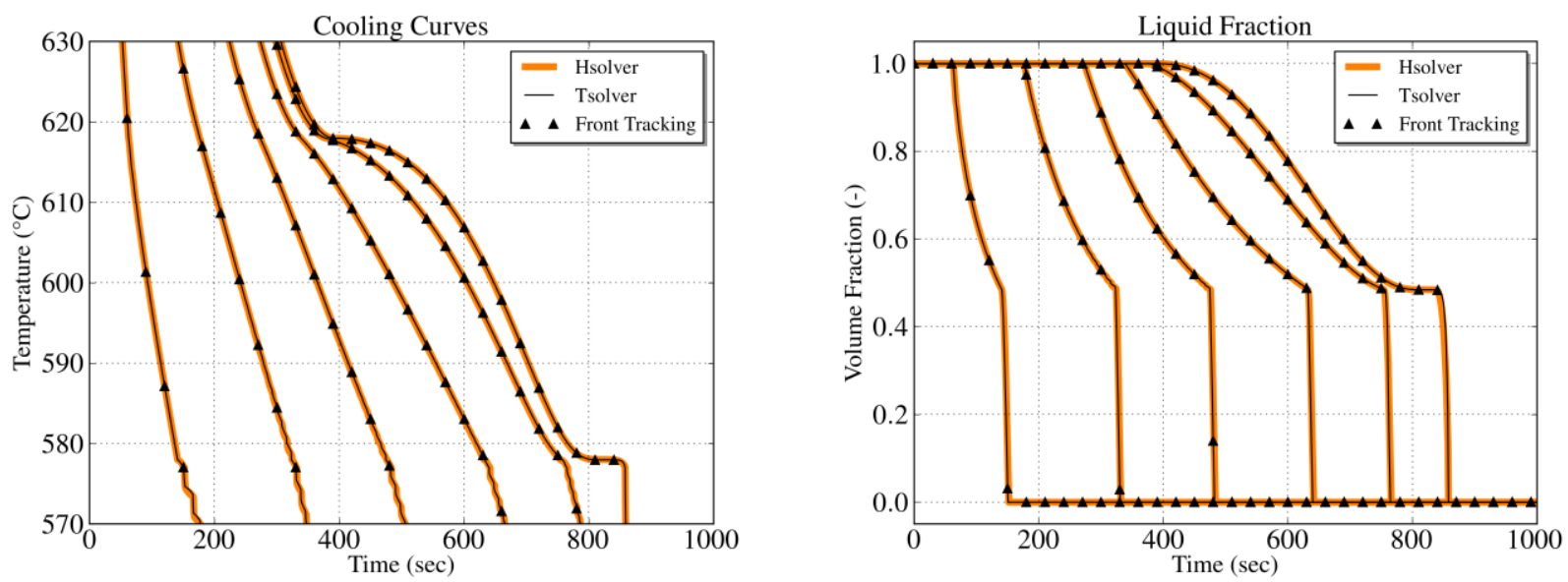

Figure 3: Computed unidirectional heat diffusion during solidification of an $\mathrm{Al}-7 \mathrm{wt}$ \% Si alloy using (orange) the enthalpy method and (black) the temperature method, comparison being made for (left) cooling curves and (right) time history of the liquid fraction. Each curve corresponds to a position along the sample, from $0 \mathrm{~cm}$ (cooling side) to $10 \mathrm{~cm}$ (insulated side), with $2 \mathrm{~cm}$ spacing between the positions.

Table 2 presents the additional equations used in a second solidification benchmark with macrosegregation for a simple binary alloy ( $\mathrm{i}=1$ ). For the conservation of energy, Eq.2 is kept. Conservation equations in Table 2 are for mass, momentum and chemical species. As for energy, they are presented after the volume averaging technique has been applied [2], [14]. Moreover, an assumption of a static and non-deformable solid phase is made. Consequently, the mechanical model is reduced to the conservation of momentum in the liquid phase. This assumption also yields some other consequences on the mass balance and the liquid momentum conservation. In the latter, is the stress deviator tensor in the liquid phase. A Darcy term is added to take into account the dissipative interfacial stress in the porous-like mushy zone. Its main parameter is the permeability of the mushy zone, $\mathrm{K}$. It is considered isotropic, hence reducing to a scalar which is given by the Carman-Kozeny relation, based on the secondary dendrite arm spacing $\lambda_{2}$ :

. The liquid density being taken constant, its spatial variations as a function of temperature and average composition are still needed to compute thermosolutal convection forces. For that purpose, the Boussinesq approximation is used, considering the thermal and solutal expansion coefficients and a reference density, $<$, defined at a reference temperature and reference composition $f$. Values for the references are taken at the liquidus temperature and the nominal composition of the alloy, [10]. More details about the FE formulation can be found in [18], [19]. Also note that the macroscopic solute diffusion coefficient in the solid phase is neglected in Eq. 20. 
Table 2: Averaged conservation equations for the conservation of mass, momentum and solute mass

The Tsolver's ability to be coupled with various physical phenomena like macrosegregation and fluid flow in porous medium is displayed in this test case. It consists of a solidification benchmark where a $10 \mathrm{~cm}$ width $\times 6 \mathrm{~cm}$ height $\times 1 \mathrm{~cm}$ thick cavity containing a $\mathrm{Sn}-3 \mathrm{wt} . \% \mathrm{~Pb}$ melt is cooled down from its two narrowest vertical sides using heat exchangers (LHE: left heat exchanger, RHE: right heat exchanger). The experiment, inspired by Hebditch and Hunt's [20] similar set up, has been revisited by Hachani et al. [21] who performed the solidification with better controlled conditions and using an increased number of samples for composition analysis. Recently, a successful attempt to simulate the experiment was carried out by Carozzani et al. relying on an enthalpy resolution [10]. All details regarding geometry, finite element discretization, material properties and boundary conditions can be found in the latter reference. For this computation, solidification paths, phase compositions and phase enthalpies were determined by a thermodynamic module dedicated to equilibrium calculations for binary alloys. The 3D simulation results in Figure 4 show a satisfactory agreement with the experimental temperature measurements recorded at mid-heights of the cavity and uniformly distributed along its width [10]. In fact, simulation results with the Tsolver and the Hsolver were found to be almost superimposed, as in Figure 4. Regarding the computation, the Tsolver resolution proves to be faster than the Hsolver used in [1]: a process time of 7000s required a computation time of 90 hours 13 minutes compared to 114 hours 21 minutes spent by the enthalpy resolution with 32 cores on the same cluster. The gain factor is about $20 \%$.

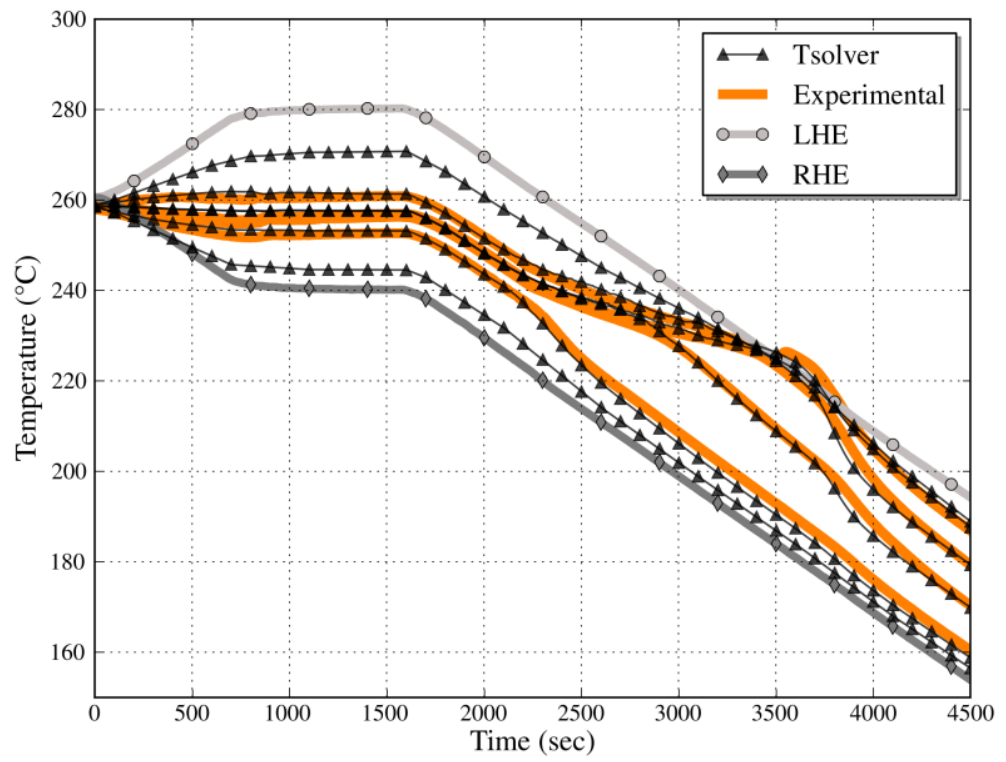

Figure 4: Experimental cooling curves overlap with the results of the 3D FE simulation. The left (LHE) and right (RHE) heat exchangers impose the boundary temperature in the experiment 


\section{Casting of a multicomponent alloy}

The efficiency of the temperature-based resolution resides in its performance when combined with thermodynamic tabulations. A multicomponent alloy consists of at least two solute elements, and therefore the tabulation size increases, hence the number of search operations also increases. To demonstrate the speed-up ability of the temperature-based approach while predicting all phase transformations during macrosegregation, we consider the solidification of a ternary alloy, $\mathrm{Fe}-2 \mathrm{wt} . \% \mathrm{C}-30 \mathrm{wt} . \% \mathrm{Cr}$. As illustrated in Figure 5a, the alloy domain has a cylinder shape close to 3 inches height $\times 1$ inch diameter. Exact values are reported in Table 3 with all material properties, initial and boundary conditions, as well as numerical parameters for the simulations. The melt steel is initially at $1395^{\circ} \mathrm{C}$. The temperature of the bottom surface is imposed with a constant decreasing rate of $0.1 \mathrm{~K} \cdot \mathrm{s}^{-1}$ starting with $1380{ }^{\circ} \mathrm{C}$, i.e. $40^{\circ} \mathrm{C}$ higher than the nominal liquidus temperature, as shown in Figure 5b. The other surfaces are kept adiabatic. The cylinder is held in a vertical position. In these conditions, and knowing that the carbon and chromium solutes have lightening effects on the liquid at nominal composition, the density inversion resulting from the composition gradient in the interdendritic liquid, may cause flow instability (segregation plumes) at the solidification front. While the selected alloy is a steel, this application is also representative of directional cooling in a single crystal casting, e.g. for nickel-base superalloys [22]. Figure $5 \mathrm{c}$ also provides the transformation path of the alloy at nominal composition, i.e. assuming no macrosegregation and full thermodynamic equilibrium as computed with ThermoCalc and the TCFE6 database [23], [24]. A total of 5 phases need to be handled, the characteristic temperature for their formation being reported in Figure $5 \mathrm{~b}$.

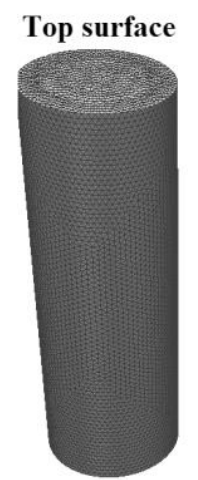

Bottom surface

(a)

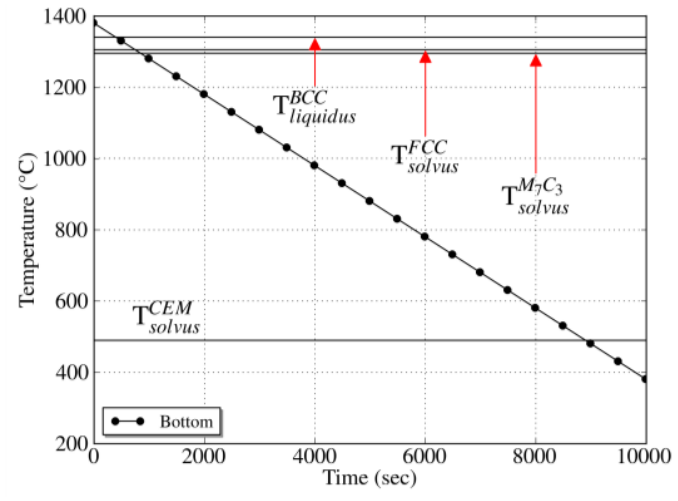

(b)

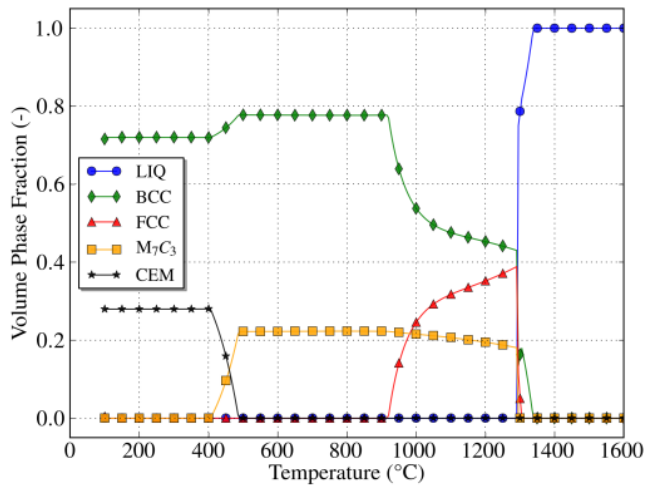

(c)

Figure 5: Configurations for directional casting of (a) a 1 inch diameter $\times 3$ inches height cylindrical domain for which (b) temperature-time conditions are imposed at its bottom surface. The alloy is $\mathrm{Fe}-2 \mathrm{wt} . \% \mathrm{C}-30 \mathrm{wt}$. \% $\mathrm{Cr}$, its computed transformation path [23], [24] at nominal composition being displayed in (c).

\section{Thermodynamic tabulations}

Full thermodynamic equilibrium is considered in the present case. Due to macrosegregation, the average composition is expected to continuously vary in time and space during casting. Transformation paths are thus determined a priori for a set of average compositions around the nominal value. Hence, carbon content is arbitrarily varied in the interval [1.8wt.\%, 2.2wt.\%] while chromium content variation is in the interval [27wt $\%, 33 \mathrm{wt} \%]$. The offset of $\pm 10 \%$ with respect to the nominal composition value allows tabulating 
relatively small composition steps to ensure a fairly accurate mapping when compared to the corresponding ternary phase diagram. The average composition step is $0.04 \mathrm{wt} . \%$ for carbon and $0.6 \mathrm{wt} \%$ for chromium, thus representing $2 \%$ intervals with respect to the nominal composition. The temperature varies in the interval $\left[100^{\circ} \mathrm{C}, 1600^{\circ} \mathrm{C}\right]$ by $5^{\circ} \mathrm{C}$ steps. For each triplet (carbon content

in wt.\% $\mathrm{C}$, chromium content in wt.\% $\mathrm{Cr}$, temperature $\mathrm{T}$ in $\mathrm{K}$ ) corresponds a phase fraction and a pair of intrinsic phase composition ). For the 5 phases listed in Figure $5 \mathrm{c}$ (LIQ $\equiv$ liquid, $\mathrm{BCC} \equiv$ ferrite, FCC $\equiv$ austenite, $\mathrm{M} 7 \mathrm{C} 3 \equiv$ carbide, $\mathrm{CEM}=$ cementite), the enthalpy and density $\phi$, are tabulated as functions of temperature and phase intrinsic composition. If this latter input lies between two tabulated values, a linear interpolation is performed to determine the output, i.e. phase enthalpy and density. With the advancement of solidification, the liquid is enriched with solute by macrosegregation, which enables new solidification paths. It means that the primary solidifying phase is not necessarily the same as when considering the nominal composition. For this reason, the tabulation approach is interesting inasmuch as it provides phase transformation paths and values of phase properties that are compatible with the system's actual composition. Figure 6 summarizes the tabulated thermodynamic data for two sets of average composition for the considered ternary system. Note that in the present test case, phase densities are taken constant $\left(\rho^{s}=\rho^{l}=6725 \mathrm{~kg} \cdot \mathrm{m}^{-3}\right)$. Therefore they are not tabulated. With this assumption, no shrinkage occurs upon phase change.

\begin{tabular}{|c|c|c|c|}
\hline Parameter & Symbol & Value & Unit \\
\hline \multirow[t]{2}{*}{ Nominal composition } & & 2 & wt.\% \\
\hline & & 30 & wt.\% \\
\hline Characteristic temperatures & $\mathrm{T}_{\text {top }}, \mathrm{T}_{\text {bottom }}$ & Figure $5 b$ & ${ }^{\circ} \mathrm{C}$ \\
\hline Phase fraction & & Tabulations Figure 7 & - \\
\hline Phase enthalpy & & Tabulations Figure 7 & $\mathrm{~J} \mathrm{~kg}^{1}$ \\
\hline Phase composition & & Tabulations Figure 7 & wt.\% \\
\hline Phase composition & & Tabulations Figure 7 & wt.\% \\
\hline \multirow[t]{2}{*}{ Diffusion coefficients } & & $15 \cdot 10^{-10}$ & $\mathrm{~m}^{2} \mathrm{~s}^{-1}$ \\
\hline & & $15 \cdot 10^{-10}$ & $\mathrm{~m}^{2} \mathrm{~s}^{-1}$ \\
\hline Dynamic viscosity & & $2 \cdot 10^{-3}$ & $\mathrm{~Pa} \mathrm{~s}$ \\
\hline \multirow[t]{2}{*}{ Solutal expansion coefficient } & & $1.54 \cdot 10^{-3}$ & $\mathrm{wt} \%^{-1}$ \\
\hline & & $1.72 \cdot 10^{-2}$ & $\mathrm{wt} \%^{-1}$ \\
\hline Thermal expansion coefficient & & $8.96 \cdot 10^{-5}$ & ${ }^{\circ} \mathrm{C}^{-1}$ \\
\hline Thermal conductivity in the solid & & 40 & $\mathrm{~W} \mathrm{~m}^{-1}{ }^{\circ} \mathrm{C}^{-1}$ \\
\hline Thermal conductivity in the liquid & & 28 & $\mathrm{~W} \mathrm{~m}{ }^{-1}{ }^{\circ} \mathrm{C}^{-1}$ \\
\hline Dendrite arm spacing & & $60 \cdot 10^{-6}$ & $\mathrm{~m}$ \\
\hline Density & & 6725 & $\mathrm{~kg} \mathrm{~m}^{-3}$ \\
\hline Reference composition & & 2 & wt. $\%$ \\
\hline Reference composition & & 30 & wt. $\%$ \\
\hline Reference temperature & $f$ & 1377 & ${ }^{\circ} \mathrm{C}$ \\
\hline Initial temperature & $T_{0}$ & 1395 & ${ }^{\circ} \mathrm{C}$ \\
\hline Ingot diameter & & $25 \cdot 10^{-3}$ & $\mathrm{~m}$ \\
\hline Ingot length & & $75 \cdot 10^{-3}$ & $\mathrm{~m}$ \\
\hline FE mesh size & & $10^{-3}$ & $\mathrm{~m}$ \\
\hline Time step & & 0.1 & $\mathrm{~s}$ \\
\hline Convergence criterion (residual) & $\varepsilon_{\mathrm{R}}$ & $10^{-5}$ & - \\
\hline Convergence criterion(temperature) & $\varepsilon_{\mathrm{T}}$ & $10^{-3}$ & $\mathrm{~K}$ \\
\hline
\end{tabular}

Table 3: Parameters for solidification of alloy $\mathrm{Fe}-2$ wt.\% $\mathrm{C}-30$ wt.\% $\mathrm{Cr}$ presented in Figure 5 - 10 
Thermodynamic Tabulations for the Fe-C-Cr system

Phase Fractions

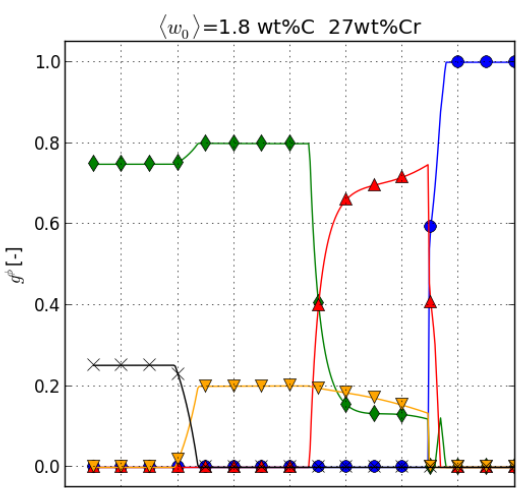

$\left\langle w_{0}\right\rangle=2.2 \mathrm{wt} \% \mathrm{C} \quad 33 \mathrm{wt} \% \mathrm{Cr}$

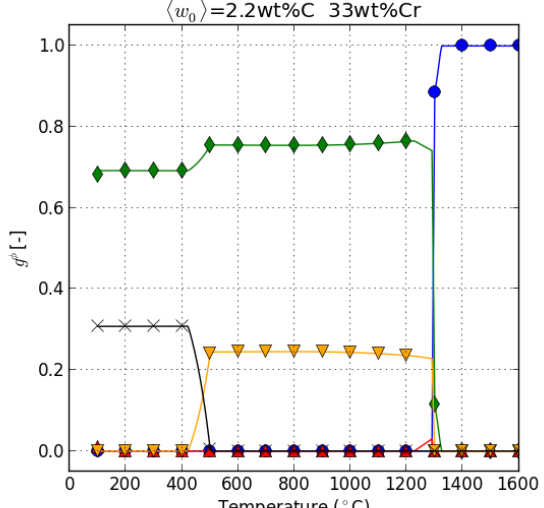

Phase Compositions (wt\% carbon)

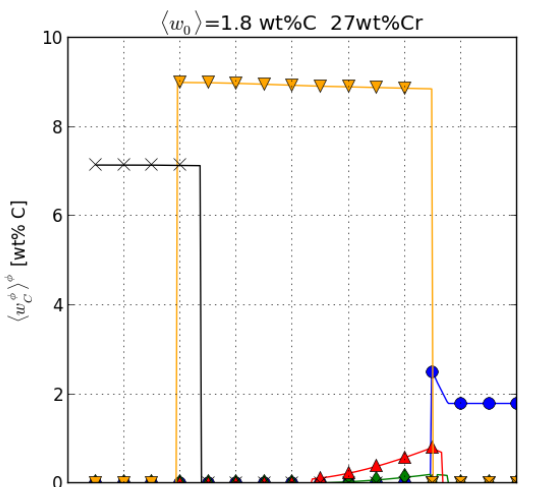

$\left\langle w_{0}\right\rangle=2.2 \mathrm{wt} \% \mathrm{C} \quad 33 \mathrm{wt} \% \mathrm{Cr}$

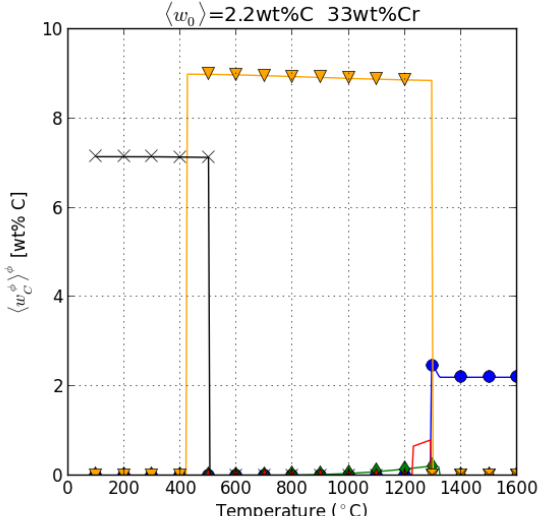

Phase Compositions (wt\% chromium)
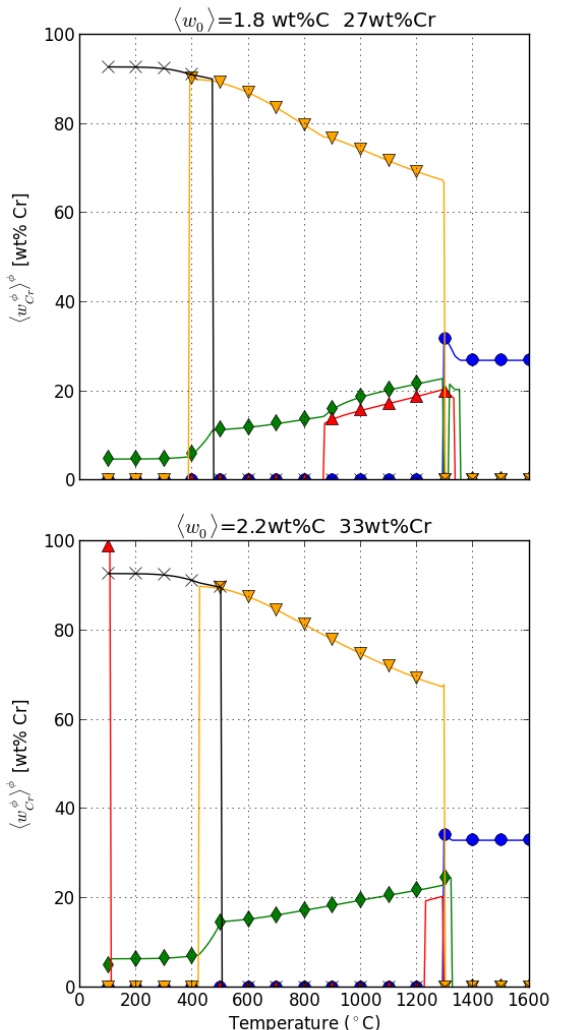
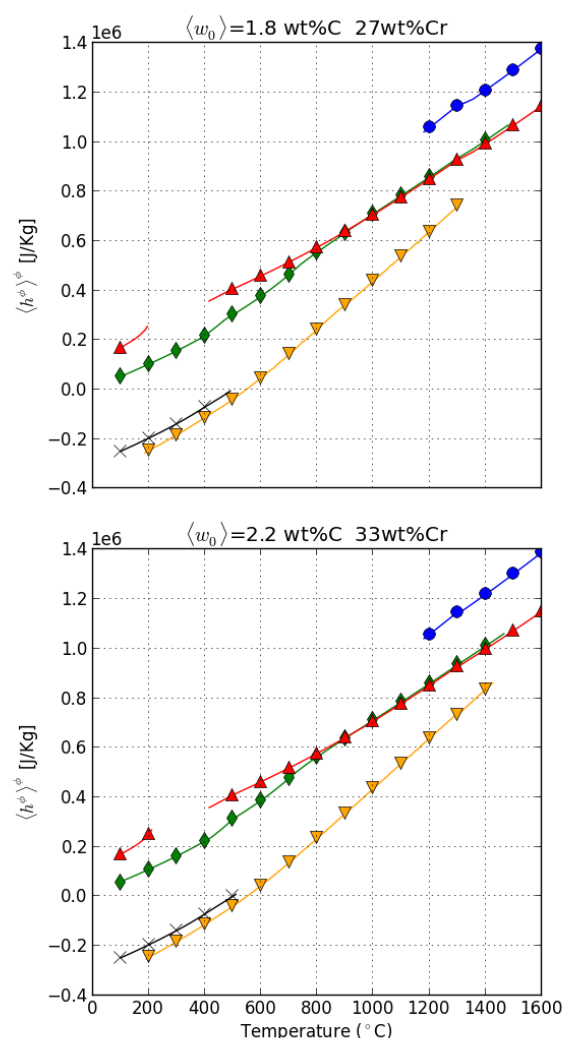

Figure 6: Tabulated thermodynamic data for the ternary system Fe-C-Cr alloy with software Thermo-Calc [23] with database TCFE6 [24] 


\section{Solidification without macrosegregation}

A first case is considered without macrosegregation, that is, all mechanical driving forces are bypassed, leading to a static melt. This is achieved by nullifying the thermal and solutal expansion coefficients, which is equivalent to a constant density in space and time, i.e. no Boussinesq force is considered. This way, the average composition may only vary due to diffusion in the liquid phase according to Eq. 20 where the convection term is neglected. Diffusion is significantly small in the present case and can be neglected too. In such a case, the composition distribution maintains a homogeneous aspect throughout the sample during the entire cooling sequence. The phase transformations then are necessarily expected to follow the unique path shown in Figure 5c. After $407 \mathrm{~s}$ of cooling, the liquidus isotherm enters the bottom surface of the geometry and starts its upward propagation, marking the solidification onset. Figure 7 presents the simulation results at 3 successive times for the distribution of the solute species and the temperature, as well as for the fraction of phases listed in Figure 5c. At $600 \mathrm{~s}$, a fully liquid region is still largely present while the mushy zone is made of liquid plus the primary solid phase (ferrite). At $10560 \mathrm{~s}$, the sample is full solid, with fractions of ferrite and cementite that corresponds to the values read in Figure $5 \mathrm{c}$ at low temperature. At the selected intermediate time, the presence of 4 phases is found. The solid region at the bottom of the cylinder is made of ferrite, austenite plus carbide, the temperature being still too high to permit the cementite to form. The mushy zone above the solid region is characterized by the presence of 3 phases due to a peritectic reaction taking place that progressively transform ferrite into austenite in the presence of liquid. It can be noticed that the phase fraction isovalues in Figure 7 (at $600 \mathrm{~s}$ ) are horizontal, owing this to two factors: the first is the temperature field, which varies unidirectionally from bottom to top, controlled by thermal diffusion, while the second is the uniform average composition throughout the sample due to the absence of convection. In fact both factors are consequences of the flow absence, which would transport heat and solute by advection, thus inevitably changing the phase distribution. The succeeding phase change is a solid-state transformation where $\alpha$-ferrite and the carbide $\mathrm{M}_{7} \mathrm{C}_{3}$ react to form cementite at $490^{\circ} \mathrm{C}$ at nominal composition, as shown in Figure 5b. The reaction is relatively slow, ending with $28 \%$ of cementite and $72 \%$ of $\alpha$-ferrite.

\section{Solidification with macrosegregation}

In this case, the artificial consideration of a still flow is dropped, hence taking into account macrosegregation caused by the fluid motion by using realistic values of the expansion coefficient given in Table 3. Solidification starts at 407 seconds when the cylinder's bottom base temperature reaches the liquidus temperature of the alloy. In fact, the solidification onset is the same as in the former case, since the average composition remains unchanged for an entirely liquid domain (assuming an initially infinite solute mixing in the melt). As shown in Figure 8 at $600 \mathrm{~s}$, the first solid phase to form remains ferrite. We can also see solute-rich channels forming in the mushy zone and solute plumes rising in the melt above the mushy zone due to a subsequent upward flow. It is actually caused by the thermosolutal buoyancy force created by the carbon and chromium solutes. Such phenomenon could delay solidification inside liquid-rich channels and results in a freckling defect [25] on the surface of the cylinder as well as inside, as shown later in this section. As solidification proceeds, the liquid becomes more enriched with solute and the peritectic reaction 
forming the austenite phase is reached. However, for very large enriched melt, it can also be observed that primary solidification proceeds with the austenite phase rather than the ferrite phase. The carbide phase can also form with the austenite phase at some locations. These observations correspond to a simulation time of $2000 \mathrm{~s}$ in Figure 8. Solidification ends at around $2475 \mathrm{~s}$, the last liquid solidifying at the cylinder's top surface, where the average composition reaches a maximum of $\mathrm{Fe}-2.151 \mathrm{wt} . \% \mathrm{C}-30.633 \mathrm{wt} . \% \mathrm{Cr}$, i.e. a relative positive macrosegregation, $\left(\left\langle w_{i}\right\rangle-\left\langle w_{i}\right\rangle_{0}\right) /\left\langle w_{i}\right\rangle_{0}$, of $7.5 \%$ for carbon and $2.1 \%$ for chromium. The fact that the maximum average composition is observed at the top, is verified in Figure 9a which shows the composition map in a $2 \mathrm{D}$ vertical slice through the longitudinal axis of the cylinder. We can also see it in Figure $9 \mathrm{~b}$ where the relative composition profile are plotted at the end of the cooling process along the longitudinal cylinder axis Z-Z' and along the axis of the freckle, F-F'. The negative segregation up to $1 \mathrm{~cm}$ from the chill corresponds to the solute depletion caused by the first solid formation. The subsequent solidification enriches further the liquid; hence the solid composition also increases. The composition evolution trend for both solutes is similar: an overall rise until positive segregation is achieved above $5 \mathrm{~cm}$ from the chill. The positive macrosegregation intensifies when the profile is chosen at the center of the freckle, negative segregation then becoming less pronounced.

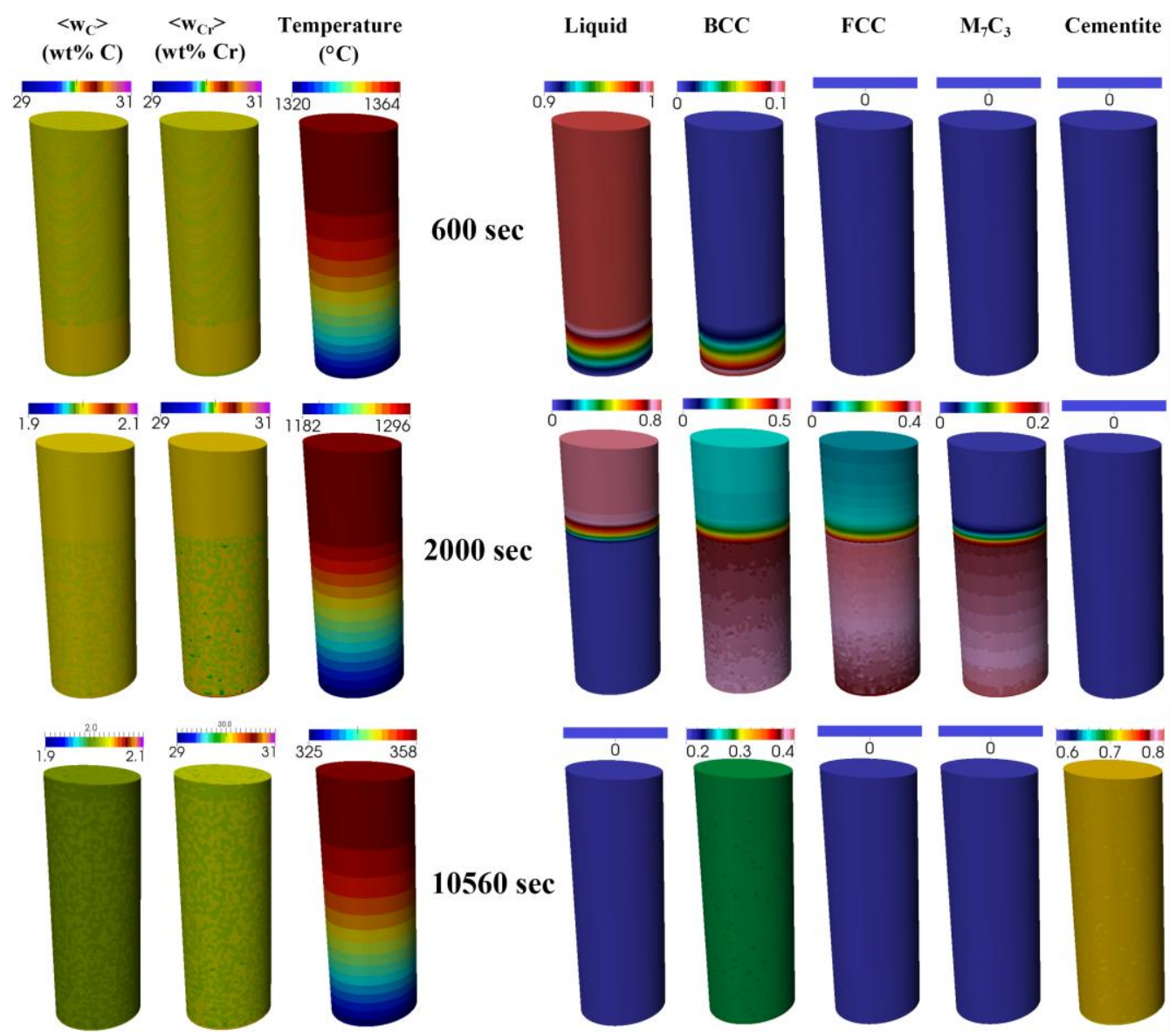

Figure 7: Upward solidification of a cylinder rod with a static liquid at 3 stages in a Fe -2 wt $\% \mathrm{C}-30 \mathrm{wt} \% \mathrm{Cr}$ alloy. The left columns show the average composition and temperature distribution, while the right columns show the phase fractions 


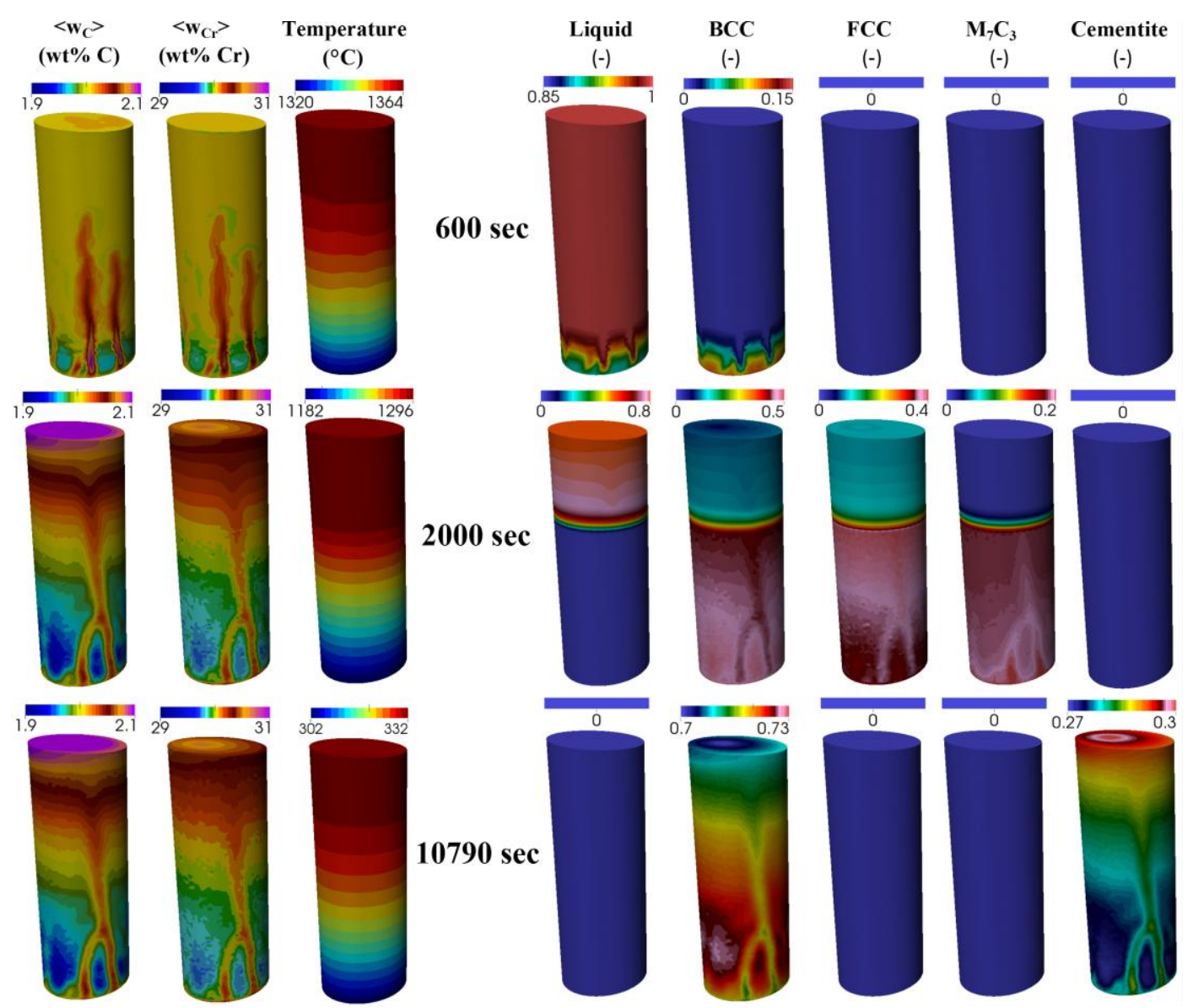

Figure 8: Upward solidification of a cylinder rod at 3 stages showing the metallurgical consequences of macrosegregation in a $\mathrm{Fe}-2 \mathrm{wt} \% \mathrm{C}-30 \mathrm{wt} \% \mathrm{Cr}$ alloy. The left columns show the average composition and temperature distribution, while the right columns show the obtained phase fractions

Beyond 2475 seconds, no variations of the average composition maps are observed since solute diffusion in the solid phases is neglected. Nonetheless, as temperature decreases, solid-state transformations are still possible as for the case with no macrosegregation. The formation of a cementite phase begins at the cylinder base at $8843 \mathrm{~s}$ with a temperature of $496.9^{\circ} \mathrm{C}$. At about $9293 \mathrm{~s}$, the isotherm $488.5^{\circ} \mathrm{C}$ reaches the top surface. This temperature value is the local cementite solvus temperature. The difference in the solvus temperature between the bottom and top surfaces is due macrosegregation. Macrosegregation also explains the variation in the cementite content. The solid state transformation ends shortly before $10500 \mathrm{~s}$. The final phase distribution is clearly dependent on the final macrosegregation pattern. They retain the shape of the freckles that were caused by thermosolutal convection, hence demonstrating the heritage of the solidification process on the final distribution of phases. This is better illustrated by drawing the time evolution of the fraction of phases at the center of the bottom and top surfaces of the cylinder in Figure 10. With no macrosegregation, in Figure 10a, the final distribution of the phases is the same at time $12000 \mathrm{~s}$, while with macrosegregation, in Figure 10b, variations of the cementite and ferrite are revealed.

The previously mentioned segregation plumes have transformed to freckles, inside the cylinder and on the boundary. This defect is marked by a noticeable gradient of composition and phase fractions, possibly changing the mechanical properties in the channels, hence the overall mechanical behavior of the alloy [26]. 
The coupling of the Tsolver with thermodynamic tabulations is thus demonstrated. It shows the ability to predict complex solidification paths, even if only at equilibrium. As for the computation time, the Tsolver resolution performed better: 500 seconds of solidification required 6 hours 14 minutes compared to 8 hours 6 minutes spent by the enthalpy resolution with 12 cores on the same machine. The gain factor is about $22 \%$.
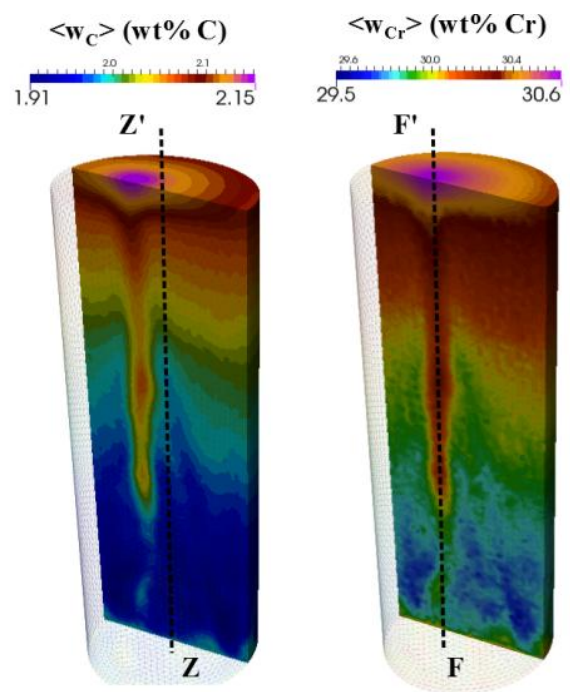

(a)

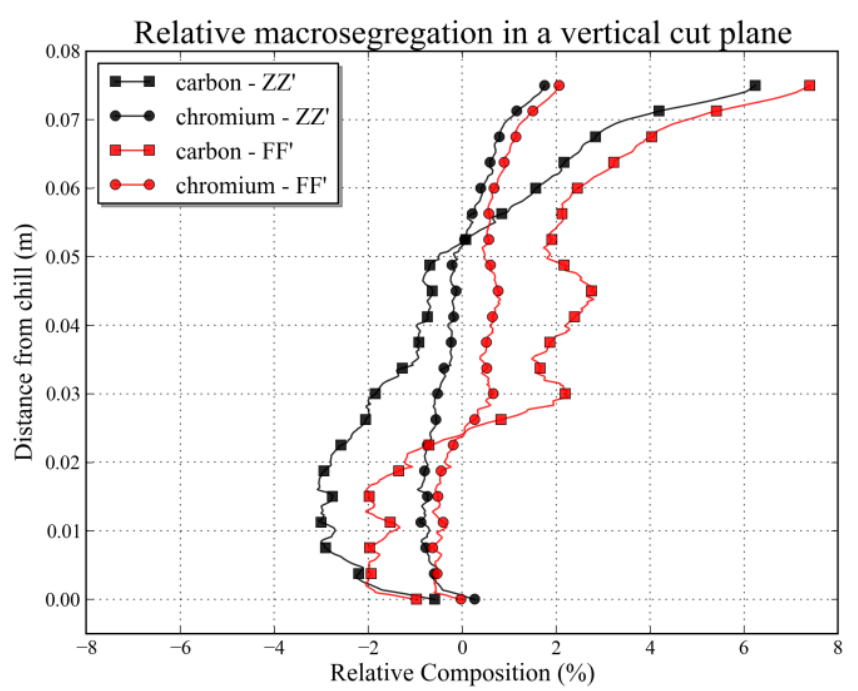

(b)

Figure 9: (a) average composition map on a vertical section inside the sample, with

(b) relative macrosegregation profiles on the vertical revolution axis
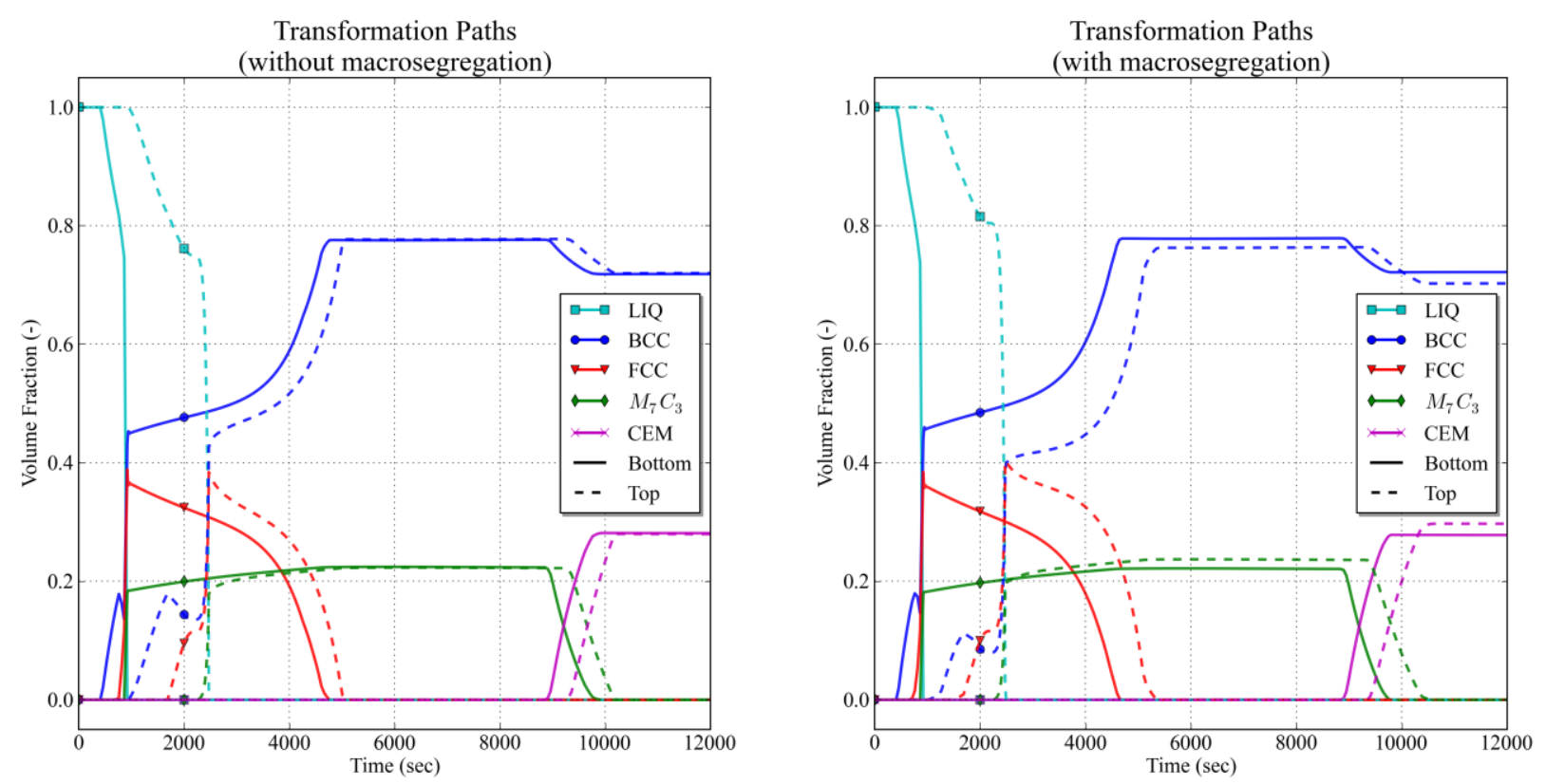

Figure 10: History of phase fraction (a) without macrosegregation and (b) with macrosegregation at the center of the (plain) bottom and (dashed) top surfaces of the cylinder surfaces, extracted from simulation displayed in (a) Figure 7 and (b) Figure 8 


\section{Conclusions}

A new algorithm for solving the energy balance has been presented. It is particularly suited for solidification problems with macrosegregation. Tabulated thermodynamic data makes it possible to predict several solidification paths for a range of average compositions. The algorithm, based on a temperature-stepping resolution, is compared to a classical enthalpy solver with the same tabulated properties for phase fractions, compositions and enthalpies. Validation has been performed with a 1D pure diffusion solidification case, as well as a 3D case with macrosegregation, the alloys being binary in both cases. A demonstration has then been shown with an iron-carbon-chromium ternary alloy.

The temperature-based method proved to be faster in computation time in all cases. Coupling with the prediction of grain structure is presently under development [27], considering the importance already demonstrated elsewhere [10], [17]. Besides, this article only presents tabulations used with the approximation of full equilibrium -or lever rule- for macrosegregation calculations. Only for the test case considering pure diffusion in Al-7wt\%Si the Gulliver-Scheil path was considered. For this particular alloy, there is little difference between these two paths. And in case of macrosegregation in binary systems such as $\mathrm{SnPb}$ and $\mathrm{PbSn}$ alloys, literature shows that little difference is found [28]. It is clear however that this approximation remains limiting for multicomponent alloys. For steels, a third type of approximation is even required, named partial equilibrium, that considers equal chemical potential of interstitial elements in all phases (e.g., C), while substitutional species in the solid phases (e.g., Cr) are frozen [29].

\section{Acknowledgements}

This work was funded by the European Space Agency under the projects CCEMLCC (grant AO-2004-017) and NEQUISOL (grant AO-1999-023) aiming to study containerless solidification of alloys in microgravity conditions.

\section{References}

[1] C. Beckermann, "Modelling of macrosegregation: applications and future needs," Int. Mater. Rev., vol. 47, no. 5, pp. 243-261, 2002.

[2] J. A. Dantzig and M. Rappaz, Solidification. EPFL Press, 2009.

[3] G. Lesoult, C.-A. Gandin, and N. T. Niane, "Segregation during solidification with spongy deformation of the mushy zone," Acta Mater., vol. 51, no. 18, pp. 5263-5283, Oct. 2003.

[4] G. Lesoult, C.-A. Gandin, and N. T. Niane, "Erratum to 'Segregation during solidification with spongy deformation of the mushy zone' [Acta Materialia 51 (2003) 5263-5283]," Acta Mater., vol. 52, no. 2, p. 531, Jan. 2004.

[5] M. C. Flemings and G. E. Nereo, "Macrosegregation: Part I," Trans. Metall. Soc. AIME, vol. 239, pp. 1449-1461, 1967.

[6] M. Založnik and H. Combeau, "An operator splitting scheme for coupling macroscopic transport and grain growth in a two-phase multiscale solidification model: Part I - Model and solution scheme," Comput. Mater. Sci., vol. 48, no. 1, pp. 1-10, Mar. 2010.

[7] M. Založnik, A. Kumar, and H. Combeau, "An operator splitting scheme for coupling macroscopic transport and grain growth in a two-phase multiscale solidification model: Part II - Application of the model," Comput. Mater. Sci., vol. 48, no. 1, pp. 11-21, Mar. 2010.

[8] C. R. Swaminathan. and V. R. Voller, "On The Enthalpy Method," Int. J. Numer. Methods Heat Fluid 
Flow, vol. 3, no. 3, pp. 233-244, Dec. 1993.

[9] M. Bellet, H. Combeau, Y. Fautrelle, D. Gobin, M. Rady, E. Arquis, O. Budenkova, B. Dussoubs, Y. Duterrail, A. Kumar, C. A. Gandin, B. Goyeau, S. Mosbah, and M. Založnik, "Call for contributions to a numerical benchmark problem for 2D columnar solidification of binary alloys," Int. J. Therm. Sci., vol. 48, no. 11, pp. 2013-2016, Nov. 2009.

[10] T. Carozzani, C.-A. Gandin, H. Digonnet, M. Bellet, K. Zaidat, and Y. Fautrelle, "Direct Simulation of a Solidification Benchmark Experiment," Metall. Mater. Trans. A, vol. 44, no. 2, pp. 873-887, Feb. 2013.

[11]X. Doré, H. Combeau, and M. Rappaz, "Modelling of microsegregation in ternary alloys: Application to the solidification of Al-Mg-Si," Acta Mater., vol. 48, no. 15, pp. 3951-3962, Sep. 2000.

[12]Q. Du, D. G. Eskin, and L. Katgerman, "Modeling Macrosegregation during Direct-Chill Casting of Multicomponent Aluminum Alloys," Metall. Mater. Trans. A, vol. 38, no. 1, pp. 180-189, Jan. 2007.

[13] L. Thuinet and H. Combeau, "Prediction of macrosegregation during the solidification involving a peritectic transformation for multicomponent steels," J. Mater. Sci., vol. 39, no. 24, pp. 7213-7219, Dec. 2004.

[14] J. Ni and C. Beckermann, "A volume-averaged two-phase model for transport phenomena during solidification," Metall. Trans. B, vol. 22, no. 3, pp. 349-361, Jun. 1991.

[15]M. Rappaz, M. Bellet, and M. Deville, Numerical Modeling in Materials Science and Engineering. Springer Berlin Heidelberg, 2003.

[16]E. Süli, "Lecture Notes on Finite Element Methods for Partial Differential Equations." University of Oxford, 2000.

[17]C.-A. Gandin, "From constrained to unconstrained growth during directional solidification," Acta Mater., vol. 48, no. 10, pp. 2483-2501, Jun. 2000.

[18]B. Rivaux, "Simulation 3D éléments finis des macroségrégations en peau induites par déformations thermomécaniques lors de la solidification d'alliages métalliques," École Nationale Supérieure des Mines de Paris, 2011.

[19]T. Carozzani, "Développement d'un modèle 3D Automate Cellulaire-Éléments Finis (CAFE) parallèle pour la prédiction de structures de grains lors de la solidification d'alliages métalliques," Ecole Nationale Supérieure des Mines de Paris, 2012.

[20]D. J. Hebditch and J. D. Hunt, "Observations of ingot macrosegregation on model systems," Metall. Trans., vol. 5, no. 7, pp. 1557-1564, Jul. 1974.

[21] L. Hachani, B. Saadi, X. D. Wang, A. Nouri, K. Zaidat, A. Belgacem-Bouzida, L. Ayouni-Derouiche, G. Raimondi, and Y. Fautrelle, "Experimental analysis of the solidification of $\mathrm{Sn}-3 \mathrm{wt} . \% \mathrm{~Pb}$ alloy under natural convection," Int. J. Heat Mass Transf., vol. 55, no. 7-8, pp. 1986-1996, Mar. 2012.

[22] C. Beckermann, J. P. Gu, and W. J. Boettinger, "Development of a freckle predictor via rayleigh number method for single-crystal nickel-base superalloy castings," Metall. Mater. Trans. A, vol. 31, no. 10, pp. 2545-2557, Oct. 2000.

[23] J. O. Andersson, T. Helander, L. Höglund, P. F. Shi, and B. Sundman, "Thermo-Calc and DICTRA," Comput. Tools Mater. Sci., vol. 26, pp. 273-312.

[24]TCFE6: a thermodynamic database for different kinds of steels and Fe-based alloys. Stockholm, SE: Thermo-Calc Software AB, 2010.

[25] S. D. Felicelli, J. C. Heinrich, and D. R. Poirier, "Simulation of freckles during vertical solidification of binary alloys," Metall. Trans. B, vol. 22, no. 6, pp. 847-859, Dec. 1991.

[26] S. M. Copley, A. F. Giamei, S. M. Johnson, and M. F. Hornbecker, "The origin of freckles in unidirectionally solidified castings," Metall. Trans., vol. 1, no. 8, pp. 2193-2204, Aug. 1970.

[27] A. Saad, C.-A. Gandin, M. Bellet, N. Shevchenko, and S. Eckert, "Simulation of Freckle Formation in Directionally Solidified In - 75 wt.\% Ga - Qualitative Comparison with In Situ Observations," submitted to Metallurgical and Materials Transactions A, 2014.

[28] N. Ahmad, J. Rappaz, J.-L. Desbiolles, T. Jalanti, M. Rappaz, H. Combeau, G. Lesoult, and C. Stomp, "Numerical simulation of macrosegregation: a comparison between finite volume method and finite 
element method predictions and a confrontation with experiments," Metall. Mater. Trans. A, vol. 29, no. 2, pp. 617-630, Feb. 1998.

[29] T. Koshikawa, C.-A. Gandin, M. Bellet, H. Yamamura, and M. Bobadilla, "Computation of Phase Transformation Paths in Steels by a Combination of the Partial- and Para-equilibrium Thermodynamic Approximations," ISIJ Int., vol. 54, no. 6, pp. 1274-1282, 2014. 